\title{
Resuscitating Real Interest Rate Parity: New Evidence from Panels
}

\author{
Georgios Chortareas', George Kapetanioss,, Georgios Magkonis,
}

\begin{abstract}
This paper considers the Real Interest Rate Parity (RIRP) in OECD countries applying a sequential panel selection (SPS) method on alternative panel unit root tests. Our approach exploits the enhanced power of panels to uncover evidence of stationarity, but also identifies the exact countries for which the RIRP holds in a panel. Moreover, we construct real interest rate measures using alternative approaches, including a Markov regime-switching procedure, which is consistent with the forward-looking nature of inflation expectations formation. Considering US as the benchmark economy, we produce strong evidence of stationarity in real interest rate differentials, which resuscitates RIRP, especially given the inconclusive results in the related literature. Our results are robust to different panel unit root tests, measures of inflation expectations, and interest rate maturities. The RIRP appears quite resilient in the face of the global financial crisis and the low real interest rate environment after the great recession. The SPS allows to calculate halflives, which avoid the pitfalls of over/underestimating the speed of adjustment and are lower as compared to the typical estimates in the literature.
\end{abstract}

JEL classification: F21, F32, C23

Keywords: Real interest rate parity, Panel unit root tests, Cross-sectional dependence, Inflation expectations, Markov regime switching, Half-lives. 


\section{Introduction}

Real interest rate equalisation is broadly considered as a key criterion of international capital market integration (e.g., Frankel, 1992). Assuming no restrictions on arbitrage forces in goods and financial markets as well as rational expectations, the Real Interest Rate Parity (RIRP, henceforth) condition suggests that real rates tend to be equal across countries. Despite the intuitive appeal of the RIRP condition, the relevant empirical evidence is inconclusive and the findings in the literature during the last three decades are quite mixed. This is puzzling, given that the last 30 years before the great recession, the international capital markets went through an unprecedented process of capital flows liberalization. The removal of barriers to financial activity and cross border capital movements permeated the rationale of policy reforms that took place. This period corresponds to the Great Moderation (Bernanke, 2004). Such policies were strongly advocated by the International Monetary Fund and the World Bank.

In addition to constituting a fundamental building block of macroeconomic and financial open economy models, the real interest rate parity condition has direct implications for several policy issues. The RIRP is one of the key measures of capital mobility and it is being used as an indication of capital market integration with a global or regional focus (e.g., Lothian, 2002). Under standard assumptions in the literature, the real interest rate differential can allow the characterization of the real exchange rate (e.g., Chortareas and Driver, 2001; Nakagawa, 2002). Another branch of research highlights the implications of US interest rate policy for the interest rates of other countries (Forbes and Chinn, 2004; Frankel et al., 2004; Hausman and Wongswan, 2011). For example, Belke et al. (2016) consider the interest rate differentials to assess the impact of US quantitative easing on the interest rates. The impact of one country's interest rate on other countries' interest rates is also considered indicative of the limitations of monetary policy autonomy (e.g., Mark, 
1985). Moreover, the responsiveness of domestic interest rates to the foreign one has been the focus of analyses investigating the effects of exchange rate regimes and the "open economies trilemma" constraints (e.g., Shambaugh, 2004; Bleaney et. al., 2013).

Real interest rates have been declining globally since the 1980s. After the global financial crisis, the US nominal interest rates, along with many other key interest rates in other OECD countries, have been close to zero. As a result, real interest rates have passed into a slightly negative territory. The chronic excess of saving over investment, described as "secular stagnation" (Summers, 2015) raises the question of real interest rate adjustment. In addition to saving and investment concerns (e.g., IMF, 2014), Bernanke (2015) attributes the historically low levels of real interest rates to slow economic growth and low inflation rates. Thus, an additional challenge emerges for researchers; namely, to accurately capture the process of inflation expectations formation, which is often overlooked in the related RIRP literature. As Singh and Banerjee (2006) show, inflationary expectations are the primary reason for deviations of real interest rates from a reference world real interest rate.

This study contributes to the empirical literature in four distinct ways. First, we examine whether RIRP holds for a number of OECD economies, using the US as benchmark. To the best of our knowledge this is the first study that focuses on this set of countries. We analyse four decades of data that cover the great moderation, the high inflation period preceding it, and the great recession that followed it. Second, we exploit the panel properties of the data using the sequential panel selection (SPS) method developed by Chortareas and Kapetanios (2009). The advantage of the SPS approach consists in providing information about the stationarity of the individual series in a panel, while at the same time, exploiting the high power of the panel. Moreover, we apply this procedure to a battery of different panel unit roots tests. Third, we consider the implications of alternative measures of real interest rates. The 
related empirical literature uses a multitude of different measures, with ex post real rates and naive forecasts being the most popular. While we consider contemporaneous and ex-post approaches to the real interest rate, we also develop a measure derived from a Markov regime-switching process that captures the unobservable ex-ante interest rate. In this way, we capture inflation expectations consistent with forward-looking behaviour. Four, since the SPS procedure allows to identify the stationary real interest rate differentials in the panel we can obtain meaningful measures of the speed of convergence. In particular, we are able to calculate half-lives for the stationary interest rate differentials within our panel. This approach avoids the pitfall of calculating half-lives for all the series in a panel, which includes non-stationary series. Overall, the results on the stationarity properties of individual real interest rate differentials appear to revivify the RIRP. Our findings are robust to different panel unit-root tests, alternative concepts and definitions of inflation expectations, as well as interest rates pertaining to different maturities.

The remaining paper is structured as follows. Section 2 outlines the theoretical background and summarizes the recent literature. Sections 3 and 4 describe the methodology and the data, respectively. Section 5 analyses the construction of real interest rates, while 6 discusses the results. Section 7 provides estimates of half-lives and Section 8 concludes.

\section{Theoretical Background and Literature Review}

The real interest rate parity relies on three assumptions concerning the forecasting ability of agents and the arbitrage forces in the goods and financial markets. Denoting the exchange rate as domestic currency per unit of foreign currency, $s_{t}$, we assume that market agents form their expectations rationally, so that the 
expected change in the exchange rate is equal to the actual change plus an error term, as:

$$
\Delta s_{t}^{e}=\Delta s_{t}+\varepsilon_{t}
$$

where $\Delta s_{t}^{e}=\frac{s_{t}^{e}-s_{t-1}}{s_{t-1}}$ and $\varepsilon_{t} \sim N\left(0, \sigma_{\varepsilon}^{2}\right)$. Furthermore, assuming goods markets integration we can invoke the relative PPP condition according to which the change of the exchange rate equals the difference between the home and foreign inflation rate, denoted as $\pi_{t}$ and $\pi_{t}^{*}$, respectively (where $\pi$ is the rate of change of a price index). Thus,

$$
\Delta s_{t}=\pi_{t}-\pi_{t}^{*},
$$

If assets markets are integrated, the uncovered interest rate parity (UIRP), suggests that the difference between domestic and foreign nominal interest rates equals the expected change in the exchange rate, as

$$
i_{t}-i_{t}^{*}=\Delta s_{t}^{e},
$$

where $i_{t}$ is the nominal interest rate for the home country and $i_{t}^{*}$ is the corresponding rate for the foreign economy. Substituting (1) and (2) into (3) gives

$$
i_{t}-i_{t}^{*}=\pi_{t}-\pi_{t}^{*}+\varepsilon_{t}
$$

and rearranging we obtain: 


$$
\left(i_{t}-\pi_{t}\right)=\left(i_{t}^{*}-\pi_{t}^{*}\right)+\varepsilon_{t}
$$

or simply,

$$
r_{t}=r_{t}^{*}+\varepsilon_{t}
$$

where $r$ and $r *$ denote the home and foreign real interest rate, respectively, i.e., the difference between the nominal rate and inflation rate. Defining the real interest rate differential as $r d_{t}$, we can write:

$$
r_{t}-r_{t}^{*} \equiv r d_{t}=\varepsilon_{t}
$$

This specific form determines the econometric method that is more appropriate to test the real interest rate parity. Unless perfect capital mobility and perfect foresight hold, an adjustment period is required for real interest rate equalization. Hence, a more general stochastic model can be used to describe the behaviour of the real interest rate differential. We can write this model as:

$$
r d_{t}=a+\rho r d_{t-1}+u_{t}
$$

We can further re-parameterise (7) as:

$$
\Delta r d_{t}=a+\varphi r d_{t-1}+\sum_{i=1}^{k} \beta_{i} \Delta r d_{t-i}+u_{t}
$$

where $\varphi=\rho-1$. This form corresponds to specification of the augmented DickeyFuller (ADF) equation and the behaviour of the series depends on the estimated 
value of $\varphi$. When $\hat{\varphi}>0$, the series $r d_{t}$ is explosive and does not converge to any mean in the long run. When $\hat{\varphi}=0$, the series is a random walk containing one unit root and there is no convergence. In other words, a shock affects the variable permanently. Finally, when $\hat{\varphi}<0$, the series is stationary and converges to a zero long-run mean (when $\hat{a}=0$ ) or to a non-zero mean (when $\hat{a} \neq 0$ ). This means that a shock dies out affecting the variable only on a temporary basis.

Many studies examine the validity of real interest rate parity by employing unit root tests to consider the stationary of the real interest rate differentials $\left(r d_{t}\right)$. The traditional ADF tests, however, are subject to a number of drawbacks, such as the low power as well as possible bias, especially when there are structural breaks that have not been taken into account. ${ }^{1}$ Nevertheless, several authors use the ADF tests as a supplement to other more advanced methods. Lothian (2002) performs $\mathrm{ADF}$ tests investigating the process of financial integration from a historical perspective. His findings include evidence in favour of real interest rate parity for 10 advanced countries using both long and short term interest rates for a period of approximately two centuries. This result is in line with that of Obstfeld and Taylor (2002), who reject the null of a unit root for the period 1870-2000. Focusing on the recent float period 1974-2000, however, they cannot reject the null of a unit root. For this reason, they emphasize the importance of examining longer data samples and the usage of more powerful tests. The most popular way for increasing the power of the tests is to employ panel data. Wu and Chen (1998) and Holmes (2002) perform panel unit root tests and their results provide support to the validity of RIRP among OECD and EU countries, respectively. Similarly, Baharumshah et al. (2005) find evidence in favour of RIRP for 10 East Asian countries with respect to Japan, while

\footnotetext{
${ }^{1}$ See Perron (1989).
} 
Liew and Ling (2008) reach a similar conclusion for the same set of countries with respect to China.

On the contrary, Camarero et al. (2009) consider 19 OECD countries and find that the RIRP does not hold for either long run or short run interest rates. Their analysis is based on panel unit root and stationarity tests that take into account possible dependencies among panels. Similarly, Maveyraud-Tricoire and Rous (2009), focusing on 10 Eurozone economies, employ a panel stationarity test that takes into account both dependencies across cross-section units and possible structural breaks for the 1994-2005 period. According to their findings, the RIRP holds only after the introduction of Euro. They suggest that the convergence of money markets facilitated financial integration and, in turn, the empirical validation of RIRP.

Trying to circumvent the low-power problem of time series as well as the potential drawback of panel data, some authors use methodologies that capture structural breaks. For example, Goldberg et al. (2003), using the univariate unit root tests with one structural break, as proposed by Zivot and Andrews (1992), conclude that the RIRP holds for six major industrialized economies. Another branch of the literature focuses on the possibility of asymmetries and nonlinearities. Ferreira and Leon-Ledesma (2007) uncover the presence of considerable asymmetries concerning the real interest rate differentials; that is, the RIRD tends to behave in a different way when exceeds a specific threshold. Holmes and Maghrebi (2004) employ Smooth Transition Autoregressive (STAR) models for 4 East Asian countries with respect to Japan and US. Using short-run interest rate data, they produce evidence in support of the RIRP hypothesis. Holmes et al. (2009), applying Markov-switching unit root tests, show that the RIRP hypothesis is valid for the developed economies in their sample. Some research has also used the SPS procedure to consider interest rate differentials in Asia relative to China (Liu et al., 2013), in Latin America relative to 
the US (Zhang et al., 2014), and in Eastern European countries relative to US (Chang, 2014). All these papers use exactly the same methodology, applying the SPS procedure to a panel version of the nonlinear unit root test of Kapetanios et al. (2003).

A related, but often overlooked, issue is which nominal interest rate should be used in testing the RIRP. Pipatchaipoom and Norrbin (2010) suggest that the method employed in constructing the real interest rates affects the results. The literature, however, does not provide a clear indication and empirical studies that use either long or short maturity rates give mixed results (e.g., Lothian, 2002; Camarero et al., 2009).

\section{Methodology}

In this section, we provide a brief account of the sequential panel selection method (henceforth SPS) developed by Chortareas and Kapetanios (2009). An important advantage of the SPS is the ability to identify which series from the panel are stationary, while also taking advantage of the enhanced power of the panel data. We use three different panel unit root tests; namely, a) Im et al. (2003), b) Pesaran (2007) and c) Chang and Song (2009), (henceforth IPS, PES and CS, respectively). Below we report the testing equations along with the corresponding statistics of these three tests, namely;

IPS: $\Delta y_{i, t}=a+\beta y_{i, t-1}+\sum_{j=0}^{p} \gamma_{j} \Delta y_{i, t-j}+\varepsilon_{i, t}, \quad t_{I P S}=\frac{\sqrt{N}\left(\bar{t}-E\left(t_{i}\right)\right)}{\operatorname{Var}\left(t_{i}\right)}$,

where $N$ is the number of cross-sectional units and $\bar{t}$ is the corresponding average, i.e., $\bar{t}=N^{-1} \sum_{i=1}^{N} t_{i}$, with $t_{i}$ being the individual ADF $t$-statistic. $E\left(t_{i}\right)$ and $\operatorname{Var}\left(t_{i}\right)$ are the mean and the variance of $\bar{t}$, respectively. 
PES: $\Delta y_{i, t}=a_{i}+\beta_{i} y_{i, t-1}+c_{i} \bar{y}_{t-1}+\sum_{j=0}^{p} d_{j} \Delta \bar{y}_{t-j}+\varepsilon_{i, t}, \quad t_{C I P S}=N^{-1} \sum_{i=1}^{N} t_{i}$,

where, $\bar{y}_{t}=N^{-1} \sum_{j=1}^{N} y_{j, t}$ is the cross-sectional average of $y_{i, t}$.

CS: $\Delta y_{i, t}=\beta_{i} y_{i, t-1}+\sum_{k=0}^{p_{i}} f_{i, k} \Delta y_{i, t-k}+\sum_{k=0}^{q_{i}} g_{i, k} w_{i, t-k}+\varepsilon_{i, t}, \quad S_{\min }=\min _{1 \leq i \leq N} t_{i}$,

where $w$ are lagged differences of the remaining cross sections and linear combinations of the lagged levels of all cross sections.

The IPS test statistic (equation 9) is the average of individual ADF unit root tests and is normally distributed. The IPS test, however, assumes that no dependencies among series exist. Such dependencies may have distorting effects on statistical inference. Pesaran (2007) remedies this drawback by incorporating the lag of the cross-sectional mean of $y_{i, t}$. Estimating equation (10) for each single crosssection unit, one can obtain the test statistic as the cross-sectional average of the $t$ ADF statistics. Apart from possible cross-sectional dependencies, Chang and Song (2009) point out another possibility that may cause severe distortions. That is, the presence of cointegration across cross-sectional units. The test, as described in (11), is designed to alleviate the side effects of cointegration on the validity of the ADF unit root test.

These three tests assume that under the null hypothesis all variables that constitute the panels are I(1). Such a conclusion, however, can be rather misleading as some variables may be stationary but quite persistent. Overall, even if the vast majority of variables are in fact non-stationary, the information provided from panel tests is limited as there is no information about the individual series. The SPS method constitutes an attempt to remedy for this inadequacy. 
The first step of the procedure can be implemented accommodating any panel unit root test. If the null is not rejected, then the procedure stops accepting the nonstationarity of the series. On the other hand, if the null is rejected, we calculate the individual tests and remove the series for which there is strongest evidence for stationarity. Then, we run again the panel test using all the series except for the one just removed. We repeat this process until either the panel test does not reject the null or all the series are found to be stationary and, thus, removed from the panel. At the end of the SPS procedure we obtain two sets of series; the stationary and the nonstationary ones ${ }^{2}$.

At this point, the main contribution of the SPS is clear. While a rejection of the null hypothesis based on a panel unit root does not inform us about the series which are truly stationary, SPS provides information concerning individual series. This makes the outcomes from SPS and univariate unit root tests comparable. At the same time, the results do not suffer from low power as the method is based on panels.

The number of stationary series is an important issue of the suggested method. The most favourable case for the SPS is when the majority of series are stationary and highly persistent. In such a case, the panel tests, due to increased power, reject the null while at the same time univariate tests cannot reject it. On the other hand, the least favourable situation is when there is only a small minority of stationary cross-sectional units; panel tests tend to accept the null, while individual tests provide evidence for stationarity. In such a case, SPS tends to accept the null and, consequently, not to reveal the small proportion of stationary series. Of course, there are situations that lie in the middle between these two extreme scenarios. Chortareas and Kapetanios (2009) provide the theoretical asymptotic properties of the SPS procedure.

\footnotetext{
${ }^{2}$ For the IPS we use 5\% as level of significance, while for the PES and CS, we use the tables provided by Pesaran (2007) and Chang and Song (2009), respectively.
} 


\section{Data}

We use monthly data from the International Financial Statistics (IFS). We construct the inflation series as the growth rate of the Consumer Price Index (CPI). Our analysis considers both long and short run nominal interest rates. In particular, we use 10-year government bonds for yields of long maturity, while for the rates of short maturity we consider either the money market rates or the Treasury Bill Rate depending on the data availability. We examine 20 developed OECD countries, namely: Austria, Belgium, Canada, Denmark, Finland, France, Germany, Ireland, Italy, Japan, South Korea, Luxemburg, Mexico, Netherlands, Portugal, Spain, South Africa, Sweden, Switzerland and UK. The reference country is the US and the period considered spans from $1976 \mathrm{~m} 11$ to $2014 \mathrm{~m} 12$.

\section{Constructing the Real Interest Rate}

With a view to testing the robustness of our results we use three different ways to compute the real interest rates. The first measure assumes a naive inflation forecast and subtracts the current inflation from the current nominal rate, i.e.,

$$
r_{t}=i_{t}-\pi_{t}
$$

We call it 'contemporaneous' real interest rate. The second measure corresponds to a perfect inflation forecast and construct the 'ex post' real rates by using the actual inflation rate observed 12 months ahead, i.e.,

$$
r_{t}=i_{t}-\pi_{t+12}
$$

Finally, we calculate an 'ex ante' real interest rate using as a measure of expected inflation the 12-step ahead forecasts from a Markov switching model. That is, 


$$
r_{t}=i_{t}-E_{t} \pi_{t+12}
$$

Before proceeding further, we briefly describe the derivation of the inflation forecasts, which constitutes a key contribution of the paper. Based on a Markov switching model, we assume that there is an unobserved random variable $s$, which takes discrete values. Thus, we separate the series into a discrete number of states/regimes in the sense that each observation belongs to one of these regimes. The general model that we employ is written as

$$
\pi_{t}=c\left(s_{t}\right)+\alpha\left(s_{t}\right) \pi_{t-1}+\ldots+\omega\left(s_{t}\right) \pi_{t-k}+\varepsilon_{t}, \varepsilon_{t} \sim N\left(0, \Sigma\left(s_{t}\right)\right)
$$

where $s_{t}$ is the unobserved variable and takes discrete values $1,2,3, \ldots, M$, informing us about the number of the regimes. When $S_{t}=S_{1}$, then

$$
\pi_{t}=c\left(s_{1}\right)+\alpha\left(s_{1}\right) \pi_{t-1}+\ldots+\omega\left(s_{1}\right) \pi_{t-k}+\varepsilon_{t},
$$

with $\varepsilon_{t} \sim N\left(0, \Sigma\left(s_{1}\right)\right)$. This is the description of the first regime. The underlying idea is that there is uncertainty on whether the regime is true for each time period. Subsequently, the next step obtains estimates for the probability of each regime for every observation $t$. This process is called "probabilistic inference" because it results in the estimated probabilities of each regime. ${ }^{3}$

\footnotetext{
3 There are three sets of these probabilities; the inference, the smoothed, and the forecast ones. For more details, see Hamilton (1990) and for a concise review see Franses and van Dijk (2000).
} 
Following Krolzig (1997) and experimenting with all possible models we derive the most appropriate model for each inflation series. Given the above analysis and assuming two regimes, the expected series one period ahead can be written as:

$$
\begin{aligned}
& E\left(\pi_{t+1} \mid \Omega_{t}\right)=\operatorname{Pr}\left(s_{t+1}=1 \mid \Omega_{t}\right) *\left[\hat{c}\left(s_{1}\right)+\hat{\alpha}\left(s_{1}\right) \pi_{t}+\hat{\beta}\left(s_{1}\right) \pi_{t-1}\right], \\
& +\operatorname{Pr}\left(s_{t+1}=2 \mid \Omega_{t}\right) *\left[\left(\hat{c}\left(s_{2}\right)+\hat{\alpha}\left(s_{2}\right) \pi_{t}+\hat{\beta}\left(s_{2}\right) \pi_{t-1}\right]\right.
\end{aligned}
$$

where $\Omega_{t}$ is the informational set that includes all the observations of the sample, i.e. $\Omega_{t}=\left\{\pi_{t}, \pi_{t-1}, \ldots, \pi_{0}\right\}, \operatorname{Pr}\left(s_{t+1}=i \mid \Omega_{t}\right)$ is the forecast probability that the next period the

regime $i$ will occur and the term $\hat{c}\left(s_{i}\right)+\hat{\alpha}\left(s_{i}\right) \pi_{t}+\hat{\beta}\left(s_{i}\right) \pi_{t-1}$ is the estimated model for the regime $i$, where $i=1,2$. Accordingly, the 12-month ahead forecasts can be derived in similar way, i.e.,

$$
\begin{aligned}
& E\left(\pi_{t+12} \mid \Omega_{t}\right)=\operatorname{Pr}\left(s_{t+12}=1 \mid \Omega_{t}\right) *\left[\hat{c}\left(s_{1}\right)+\hat{\alpha}\left(s_{1}\right) \pi_{t+11}+\hat{\beta}\left(s_{1}\right) \pi_{t+10}\right], \\
& +\operatorname{Pr}\left(s_{t+12}=2 \mid \Omega_{t}\right) *\left[\left(\hat{c}\left(s_{2}\right)+\hat{\alpha}\left(s_{2}\right) \pi_{t+11}+\hat{\beta}\left(s_{2}\right) \pi_{t+10}\right]\right.
\end{aligned}
$$

From the above, it is evident that this proxy of expectations has a forward element, as it incorporates the possibility of future changes in the process of inflation; that is, the changes in the regimes.

\section{Empirical Results}

We present the results of the SPS incorporating the IPS, PES and CS panel unit root tests, along with the results from their univariate versions. In particular, the first test is the panel test of Im et al. (2003) along with its univariate form being the standard ADF test. We treat this test as the benchmark. The IPS test, however, ignores the implications of any possible dependencies among the cross-sectional units. This 
motivates the use of the test proposed by Pesaran (2007), which accounts for dependence among the countries considered in our panel. The third test, designed by Chang and Song (2009), is used to obtain results that take into account not only dependencies among units but also among cross-sectional cointegrating relationships. One drawback of this test can be its sensitivity to the ordering of the series. In order to examine whether this affects our results, we run the same test using the reverse ordering (Chortareas and Kapetanios, 2009). To determine the number of lags used in each test, we adopt the data-dependent lag structure using the sequential testing approach of $\mathrm{Ng}$ and Perron (1995).

Table 1 presents the tests discussed above for the 'contemporaneous' long real rates. Each column labelled "Univ" presents the series for which the null hypothesis of unit root is rejected when we use the corresponding univariate test. Similarly, each column named "Panel" shows the series for which the null is rejected using the SPS. The panel consists of the long run rates for 17 economies. ${ }^{4}$

$<$ Table 1 here $>$

We first consider the real interest rate differential that emerges under the assumption of the contemporaneous inflation measure. Starting from the simple ADF tests, we observe that 10 out of 17 series are stationary. When we perform the SPS using the corresponding panel test (IPS), however, we obtain stronger evidence for RIRP, as the number of stationary series is now 13. The evidence from the PES test is somewhat different. The univariate version of the test shows that now only 8 stationary series exist in the panel. The SPS panel test restores RIRP, revealing that almost all real interest rate differentials are stationary. Similarly, the CS test shows that the majority of the series in the panel are stationary. Overall, Table 1 reveals that

\footnotetext{
${ }^{4}$ We do not include Finland, Spain and Mexico due to lack of data.
} 
in all specifications, the number of stationary series in our sample increases when the SPS procedure is used. Moreover, all the series that emerge as stationary under the univariate framework continue to be stationary under the SPS. The CS test with the reverse ordering provides almost the same results with slight changes. Overall, the SPS gives significantly stronger evidence in support of RIRP, regardless of the specific unit root test applied.

To examine whether the global financial and economic crisis affects the validity of the results we run the same tests restricting our sample period to 1976m11-2008m6. We present the pre-crisis results in Table 2 which reveals that the evidence remains almost unaffected. The only discernible difference is that according to the ADF tests the number of stationary real interest rate differentials decreases. We use the "before crisis" sample for the examination of all real interest rates considered here. The results are identical with those obtained from the whole sample. So, the economic crisis does not seem to have affected the degree of convergence among real interest rate differentials. ${ }^{5}$

\section{$<$ Table 2 here $>$}

The next step of our analysis focuses on the 'ex post' long run real interest rate differentials and the corresponding results appear in Table 3. Both univariate and panel IPS tests show significant evidence in favour of RIRP as the majority of series are stationary. These results should be treated with caution since the tests do not account for dependencies among the cross-sectional units. The PES panel test, however, provides strong evidence for stationarity while correcting for dependencies revealing that 17 series are stationary versus 6 series suggested by the corresponding univariate test. The comparative profiles of the univariate and panel

\footnotetext{
${ }^{5}$ We do not report these results, but they are available upon request.
} 
tests' results are similar to those obtained from the contemporaneous measure of inflation. Furthermore, the even more demanding CS test finds that 13 series are stationary as compared to the 8 indicated by the corresponding univariate version. The evidence in favour of real interest rate differentials stationarity is further corroborated by the results from the robust CS test, which provides almost identical output. Again, it is noteworthy that all series identified as stationary by the univariate tests are also identified as stationary by the panel method, testifying to their consistency across the various tests. The panel tests, however, produce scientifically stronger evidence in favour of the stationary of real interest rate differentials.

$<$ Table 3 here $>$

Finally, we consider the real interest rate differentials constructed on the basis of the 'ex ante' real rates. We use a Markov regime-switching methodology to approximate inflation expectations for a twelve-month horizon. Given the forwardlooking nature of the 'ex ante' real rates, they emerge as the most theoretically consistent choice for the construction of the real interest rate differentials. We present the corresponding results in Table 4. As with the interest rate differentials based on "contemporaneous" and "ex post" inflation measures, the SPS approach tends to reject the unit root more frequently than the univariate test does. Thus, the panel tests can uncover more evidence of stationarity. Once more, all series for which the univariate tests reject the null emerge also stationary from the SPS panel tests.

$<$ Table 4 here $>$

We consider the robustness of our results to the maturity of the interest using the short term interest rates in our specification. We construct a panel for the period 
1979m1-2014m12 consisting of interest rate differentials for 14 countries. ${ }^{6}$ The crosssectional dimension of the panel is slightly different due to data availability. As in the case of long term interest rates, the results show that the SPS allows significantly stronger evidence that validate RIRP. The individual tests identify as stationary only a fraction of the series for which the SPS panel rejects the unit root. The three panel tests provide significant evidence in favour of RIRP. It is worth noting that the least number of stationary differentials is 10 out of 14 (see Table 5, CS test). Overall, the SPS panel approach reveals significantly enhanced evidence of stationarity. These findings are robust regardless the maturity of the real interest rate considered. The results for the contemporaneous real rates in Table 5 are quite similar with those reported in Table 6 ('ex post' rates) and Table 7 ('ex ante' rates) 7 . Finally, restricting the sample period up to the first six months of 2008 does not reveal any significant difference between the pre-crisis and post-crisis periods.

\author{
$<$ Table 5 here $>$ \\ $<$ Table 6 here $>$ \\ $<$ Table 7 here $>$
}

\title{
7. Overcoming Pitfalls in Calculating Half-Lives
}

The overall results from the SPS panel approach provide strong evidence of real interest rate differential stationarity and therefore in favour RIRP for the OECD

\footnotetext{
${ }^{6}$ These are Belgium, Canada, Denmark, Finland, France, Germany, Italy, Japan, Korea, Mexico, South Africa, Spain, Switzerland and UK.

7 In the case of short run ex ante rates, the IPS univariate and panel tests find the same stationary series. Such a finding cannot be excluded as an outcome of the testing procedure. The most probable reason is IPS test inability to take into account any potential cross-sectional dependencies, as we mention in Section 3.
} 
panel. That is, the real interest rates tend to converge. A popular measure for assessing the speed of convergence of a series' deviation from its long run mean is the half-life. In our case, the half-life assesses the speed of adjustment towards long run RIRP. The commonly used formula for the half-life is

$$
h=\frac{\ln (0.5)}{\ln (\hat{\rho})},
$$

where $\hat{\rho}$ is the estimated autoregressive coefficient of an autoregressive process of order one and $h$ equals the time that it takes for the impact of a shock to dissipate by half (e.g., Chortareas and Kapetanios, 2013).

It is straightforward to calculate half-lives of the real interest rate differentials that emerge as stationary from univariate unit-root tests. Relying on univariate unitroot tests, however, may underestimate the evidence in favour of RIRP because the tests may lack power to reject the null. The panel unit root tests may remedy this problem but they are not free from pitfalls either. The null in panel unit-root tests is that all series have a unit root. Rejecting the null does not necessarily imply that all series in the panel are stationary. As a result, in a panel with $n$ series the test can reject the unit-root null when only $n-k$ series are stationary (where $n>k$ ). In that case, calculating the half-lives of all the series in the panel, including the potentially nonstationary ones $(k)$ series, will not produce meaningful results.

Effectively, this means that a researcher confronts a trade-off in choosing between a univariate approach that allows meaningful half-life estimates and a panel approach with enhanced power to reject the null. Applying the SPS procedure to well established panel unit root tests (IPS, PES and CS) provides a straightforward solution to the above conundrum. In particular, we exploit the enhanced power of the panel unit-root tests but we are also able to accurately identify the stationary real interest rate differentials within our panel (see also, Chortareas and Kapetanios, 2009). 
Before proceeding to our results, it would be worth mentioning that no consensus exists on the degree of mean reversion in RIRP. Holmes (2002) estimates range from 2.2 to 2.6 months for the EU countries with respect to Germany. Goldberg et al. (2003) report half-life estimates equal to 2-3 quarters (6-9 months) for six developed economies. Mancuso et al. (2003), using TAR models, report a very fast speed of adjustment, ranging from 10.85 weeks (2.50 months) for the US-Canada differential to 27.71 (6.38 months) for the US-Japan differential. The half-lives are much longer, however, when the nonlinearities are not considered. Furthermore, Baharumshah et al. (2005) compute the range of estimates to be between 2.18 quarters (6.54 months) and 2.43 quarters (7.29 months) for 10 Asian economies relative to Japan. Holmes and Maghrebi (2006) find longer half-lives with the minimum value being roughly 6 months and the maximum 18 months. Ferreira and Leon-Ledesma (2007) also estimate half-lives for developing countries with an average speed of adjustment being 5.54 months and for developed economies where converge to the long-run mean is slower (16.68 months). Sekioua (2008) argues that the half-life should have an upper bound of roughly 2 years (24 months). Moreover, using median unbiased estimation, Sekioua's half-lives measures are 1.41 years (16.88 months) for the UK, 1.40 years (20.84 months) for Japan, and 1.91 years (22.95 months) for France.

Table 8 presents our half-life estimates for the OECD real interest rate differentials. The rows named "Average" report the average value of half-lives from the univariate series. The rows "Panel-All" show the panel half-lives when all the examined series in the panel are included. Finally, the rows "Panel-SPS" contain the estimates from the SPS procedure. Clearly, estimation based on panel analysis gives shorter half-lives than the average half-lives of the individually stationary series. When we compare the estimates from panel analysis with the ones from SPS, we see that the latter procedure gives even shorter half-lives. The estimates range between 
11 and 18 months for long-run rates and between 8 and 12 months for the short-run ones. Overall, the speed of converge is in the middle of the range of the existing literature.

$<$ Table 8 here $>$

\section{Summary and Conclusions}

We reconsider the validity of real interest rate parity for a panel of OECD countries using the sequential panel selection framework developed by Chortareas and Kapetanios (2009). Our analysis covers the ongoing period of globally declining (and slightly negative in some OECD countries) real interest rates and close-to-zero nominal interest rates. We use three recent panel unit-root tests against their individual series counterparts. We also employ three alternative methods for constructing real interest rates, including an ex ante measure based on a Markov switching process, which produces estimates consistent with the forward-looking nature of the implied relationship. Moreover, we consider interest rates of different maturities. Although we rely on panel unit root tests, which allow us to uncover more evidence of stationarity, we are able to avoid a typical limitation of panel unit root tests and identify the specific stationary series in our panel. By identifying the stationary real interest rate differentials in the panel, we can provide an accurate characterization regarding the validity of RIRP in the OECD economies.

Our empirical evidence strongly suggests that the majority of OECD countries' real interest rate differentials against the US are stationary. The results prove to be quite robust to different definitions of real rates and to alternative maturities. The validity of RIRP appears quite resilient in the face of the global financial crisis and the great recession. In particular, no significant differences emerge when we consider the full sample and a sub-sample that excludes the post- 
crisis period. Finally, we estimate half-lives in a manner that overcomes the limitations of measures based on either traditional individual unit-root tests or panel unit-root tests. In particular, we obtain accurate half-lives focusing only on the individual stationary series resulting from the SPS panel procedure. The half-life estimates are shorter as compared to the corresponding estimates based on the whole panel of series.

On balance, our results suggest that the real interest rate parity is rather robust for the OECD countries in our sample. The evidence testifies to a robust process of international capital market integration despite the setback of the global financial crisis and the great recession. Evidence that resuscitates the RIRP has multifaceted implications for policymaking, pertaining to the viability of independent national monetary policies, the tightness of the "open economies trilemma" constraints, the international effects of US (conventional and unconventional) monetary policy, and international policy coordination. 


\section{References}

Baharumshah, A.Z., C.T. Haw and S. Fountas. 2005. "A Panel Study on Real Interest Rate Parity in East Asian Countries: Pre- and post-liberalization era", Global Finance Journal, 16, 69-85.

Belke, A. D. Gros, and T. Osowski. 2016. "Did Quantitative Easing Affect Interest Rates Outside the US? New Evidence based on Interest Rate Differentials," Center for European Policy Studies, CEPS Working Document, No 416.

Bernanke, B. (2004). 'The Great Moderation', In: The Taylor Rule and the Transformation of Monetary Policy, Institutions Press Publication Hoover.

Bernanke, B. 2015. "Why Are Interest Rates So Low?". http://www.brookings.edu/blogs/ben-bernanke/posts/2015/03/30-why-interest-ratesso-low.

Bleaney, M., H. A. Lee, and T. Lloyd. 2013. "Testing the Trilemma: Exchange Rate Regimes, Capital Mobility, and Monetary Independence," Oxford Economic Papers, 65, 876-897.

Camarero, M., J.L. Carrion-i-Silvestre and C. Tamarit. 2009. “Testing for Real Interest Rate Parity Using Panel Stationarity Tests with Dependence: A Note," Manchester School, 77, 112-126.

Chang, H.-L. 2014. Revisiting Real Interest Rate Parity in Central and Eastern European Countries: The Sequential Panel Selection Method, Acta Oeconomica, 64, 181-196. 
Chang, Y. and W. Song. 2009. "Testing for Unit Roots in Small Panels with Short-run and Long-run Cross-sectional Dependencies," Review of Economic Studies, 76, 903-935.

Chortareas, G. and R. L. Driver. 2001. "PPP and the Real Exchange Rate-Real Interest Rate Differential Puzzle Revisited: Evidence from Non-Stationary Panel Data," Bank of England Working Papers 138, Bank of England.

Chortareas, G. and G. Kapetanio, 2009, “Getting PPP right: Identifying Meanreverting Real Exchange Rates in Panels," Journal of Banking and Finance, 33, 390-404.

Chortareas, G. and G. Kapetanios. 2013. "How Puzzling is the PPP Puzzle? An Alternative Half-Life Measure of Convergence to PPP", Journal of Applied Econometrics, 28, 435-457.

Ferreira, A. L. and M. A Leon-Ledesma. 2007. “Does the Real Interest Parity Hypothesis Hold? Evidence for the Developed and Emerging Markets," Journal of International Money and Finance, 26, 364-382.

Forbes, K. J. and M. D. Chinn. 2004. "A Decomposition of Global Linkages in Financial Markets Over Time," The Review of Economics and Statistics, 86(3): 705-722.

Frankel, J. 1992. "Measuring International Capital Mobility: A Review," American Economic Review, 82(2), 197-202.

Frankel, J., S. L. Schmukler, and L. Servén. 2004. “Global Transmission of Interest Rates: Monetary Independence and Currency Regime," Journal of International Money and Finance, 23, 701-733.

Franses, P. and D. van Dijk. 2000. Non-Linear Time Series Models in Empirical Finance, Cambridge University Press.

Goldberg, L. G, J.R. Lothian and J. Okunev. 2003. “Has International Financial Integration Increased?" Open Economies Review, 14, 299-317.

Hamilton, J. 1990. "Analysis of Time Series Subject to Changes in Regime," Journal of Econometrics, 45, 39-70. 
Hausman, J., and Wongswan, J. 2011. "Global Asset Prices and FOMC Announcements," Journal of International Money and Finance, 30, 547-571.

Holmes, M. 2002. “Does Long-run Real Interest Parity Hold Among EU Countries? Some New Panel Data Evidence," Quarterly Review of Economics and Finance, 42, 733-746.

Holmes, M. and N. Maghrebi. 2004. “Asian Real Interest Rates, Nonlinear Dynamics and International Parity," International Review of Economics and Finance, 13, 387-405.

Holmes, M. and N. Maghrebi. 2006. “Are International Real Interest Rate Linkages Characterized by Asymmetric Adjustments?" Journal of International Financial Markets, Institutions and Money, 16, 384-396.

Holmes, M., R. Dutu and X. Cui. 2009. “Real Interest Rates, Inflation and The Open Economy: A Regime-switching Perspective on Australia and New Zealand," International Review of Economics and Finance, 18, 351-360.

Im, K.S., H.Pesaran and Y. Shin. 2003. "Testing for Unit Roots in Heterogeneous Panels," Journal of Econometrics, 115, 53-74.

International Monetary Fund. 2014. World Economic Outlook: Recovery Strengthens, Remains Uneven, April, International Monetary Fund.

Kapetanios, G., Y. Shin, and A. Snell. 2003. "Testing for a Unit Root in the Nonlinear STAR Framework". Journal of Econometrics, 112: 359-379.

Krolzig, H-M. 1997. “Markov-Switching Vector Autoregressions: Modelling, Statistical Inference and Application to Business Cycle Analysis," Lecture Notes in Economics and Mathematical Systems, Springer.

Liu, Y., H.-L. Chang, and C.-W. Su. 2013. “Do Real Interest Rates Converge across East Asian Countries Based on China?" Economic Modelling, 31, 467-473. 
Lothian, J.R. 2002. “The Internationalization of Money and Finance and the Globalization of Financial Markets," Journal of International Money and Finance, 21, 699-724.

Mancuso, A.J., B.K. Goodwin and T.J. Grennes. 2003. “Nonlinear Aspects of Capital Market Integration and Real Interest Rate Equalization," International Review of Economics and Finance, 12, 283-303.

Mark, N. C. 1985. “Note on International Real Interest Rate Differentials," The Review of Economics and Statistics, 67, 681- 684.

Maveyraud-Tricoire, S. and P. Rous. 2009. "RIP and the Shift Toward A Monetary Union: Looking For a 'Euro Effect' by a Structural Break Analysis with Panel Data," Journal of International Financial Markets, Institutions and Money, 19, 336350.

Nakagawa, H. 2002. "Real Exchange Rates and Real Interest Rate Differentials: Implications of Nonlinear Adjustment in Real Exchange Rates," Journal of Monetary Economics, 49, 629 -- 649.

Ng, S. and P. Perron. 1995. "Unit Root Tests in ARMA Models with Data Dependent Methods for the Selection of the Truncation Lag," Journal of the American Statistical Association, 90, 268-281.

Obstfeld, M. and A. Taylor. 2002. “Globalization and Capital Markets," NBER Working Paper No. 8846.

Perron, P. 1989. "The Great Crash, the Oil Price Shock and the Unit Root Hypothesis," Econometrica, 57, 1361-1401.

Pesaran, H. 2007. “A Simple Panel Unit Root Test in the Presence of Crosssection Dependence," Journal of Applied Econometrics, 22, 265-312.

Pipatchaipoom, O. and S. Norrbin. 2010. "Is the Real Interest Rate Parity Condition Affected by the Method of Calculating Real Interest Rates?", Applied Economics, 42, 1771-1782. 
Shambaugh, J. C. 2004. "The Effects of Fixed Exchange Rates on Monetary Policy," Quarterly Journal of Economics, 119(1), 301-352.

Sekioua, S.H. 2008. "Real Interest Parity (RIP) over the 20th Century: New Evidence Based on Confidence Intervals for the Largest Root and the Half-Life," Journal of International Money and Finance, 27, 76-101.

Singh, M. and A. Banerjee. 2006. "Testing Real Interest Parity in Emerging Markets," IMF, Working Paper WP/06/249.

Summers. L. 2015. “On Secular Stagnation: Larry Summers Responds to Ben Bernanke”. http://www.brookings.edu/blogs/ben-bernanke/posts/2015/04/01-larrysummers-response.

Wu, J.L. and S.L. Chen. 1998. "A Re-examination of Real Interest Rate Parity," Canadian Journal of Economics, 31, 837-851.

Zhang, W.L., H.L. Chang and C.W. Su. 2014. “Do Real Interest Rates Converge across Latin American Countries?", Portuguese Economic Journal, 13, 117130.

Zivot, E. and W.K. Andrews. 1992. "Further Evidence on the Great Crash, the Oil-price Shock and the Unit Root Hypothesis," Journal of Business and Economic Statistics, 10, 251-270. 


\section{Tables}

Table 1

Stationary Series: Long Run contemporaneous real rates

\begin{tabular}{|c|c|c|c|c|c|c|c|}
\hline \multicolumn{2}{|c|}{ IPS } & \multicolumn{2}{c|}{ PES } & \multicolumn{2}{c|}{ CS } & \multicolumn{2}{c|}{ CS-rev. } \\
\hline Univ & Panel & Univ & Panel & Univ & Panel & Univ & Panel \\
\hline CAN & BEL & CAN & AUS & BEL & AUS & SWE & UK \\
\hline FRA & CAN & FRA & BEL & CAN & BEL & NET & SWI \\
\hline GER & DEN & GER & CAN & DEN & CAN & IRE & SWE \\
\hline ITA & FRA & KOR & DEN & IRE & DEN & CAN & POR \\
\hline JAP & GER & POR & FRA & ITA & IRE & BEL & NET \\
\hline KOR & ITA & SWE & GER & & ITA & & LUX \\
\hline NET & JAP & SWI & IRE & & KOR & & IRE \\
\hline POR & KOR & UK & ITA & & POR & & FRA \\
\hline SWE & NET & & JAP & & SAF & & CAN \\
\hline UK & POR & & KOR & & SWE & & BEL \\
\hline & SWE & & LUX & & SWI & & AUS \\
\hline & SWI & & NET & & & & \\
\hline & UK & & POR & & & & \\
\hline & & & SWE & & & & \\
\hline & & & SWI & & & & \\
\hline & & & UK & & & & \\
\hline & & & & & & & \\
\hline
\end{tabular}

Notes: The columns denoted "Univ" refer to the univariate versions of the corresponding tests. The columns "Panel" refer to the SPSM. IPS, Pesaran and CS stand for Im, Pesaran, Shin (2003), Pesaran (2007) and Chang-Song (2009) tests, respectively. The contemporaneous real rates are constructed as $r_{t}=i_{t}-\pi_{t}$, where $i_{t}$ and $\pi_{t}$ are the nominal interest rate and the inflation rate at time $t$, respectively. AUS: Austria, BEL: Belgium, CAN: Canada, DEN: Denmark, FIN: Finland, FRA: France, GER: Germany, IRE: Ireland, ITA: Italy, JAP: Japan, KOR: South Korea, LUX: Luxemburg, MEX: Mexico, NET: Netherlands, POR: Portugal, SAF: South Africa, SPA: Spain, SWE: Sweden, SWI: Switzerland, UK: United Kingdom. 
Table 2

Stationary Series: Long Run contemporaneous real rates-Before Crisis sample

\begin{tabular}{|c|c|c|c|c|c|c|c|}
\hline \multicolumn{2}{|c|}{ IPS } & \multicolumn{2}{c|}{ PES } & \multicolumn{2}{c|}{ CS } & \multicolumn{2}{c|}{ CS-rev. } \\
\hline Univ & Panel & Univ & Panel & Univ & Panel & Univ & Panel \\
\hline CAN & AUS & CAN & AUS & BEL & AUS & SWE & SWI \\
\hline KOR & CAN & FRA & CAN & CAN & BEL & NET & SWE \\
\hline POR & DEN & GER & DEN & DEN & CAN & LUX & SAF \\
\hline SWE & FRA & KOR & FRA & ITA & DEN & IRE & POR \\
\hline UK & GER & POR & GER & SWI & FRA & CAN & NET \\
\hline & IRE & SWE & IRE & & IRE & & LUX \\
\hline & ITA & SWI & ITA & & ITA & & IRE \\
\hline & JAP & UK & JAP & & KOR & & FRA \\
\hline & KOR & & KOR & & SAF & & CAN \\
\hline & NET & & LUX & & SWE & & BEL \\
\hline & POR & & NET & & SWI & & AUS \\
\hline & SWE & & POR & & & & \\
\hline & UK & & SWE & & & & \\
\hline & & & SWI & & & & \\
\hline & & & UK & & & & \\
\hline
\end{tabular}

Notes: The columns denoted "Univ" refer to the univariate versions of the corresponding tests. The columns "Panel" refer to the SPSM. IPS, Pesaran and CS stand for Im, Pesaran, Shin (2003), Pesaran (2007) and Chang-Song (2009) tests, respectively. The contemporaneous real rates are constructed as $r_{t}=i_{t}-\pi_{t}$, where $i_{t}$ and $\pi t$ are the nominal interest rate and the inflation rate at time $t$, respectively. AUS: Austria, BEL: Belgium, CAN: Canada, DEN: Denmark, FIN: Finland, FRA: France, GER: Germany, IRE: Ireland, ITA: Italy, JAP: Japan, KOR: South Korea, LUX: Luxemburg, MEX: Mexico, NET: Netherlands, POR: Portugal, SAF: South Africa, SPA: Spain, SWE: Sweden, SWI: Switzerland, UK: United Kingdom. 
Table 3

Stationary Series: Long Run ex post real rates

\begin{tabular}{|c|c|c|c|c|c|c|c|}
\hline \multicolumn{2}{|c|}{ IPS } & \multicolumn{2}{|c|}{ PES } & \multicolumn{2}{|c|}{ CS } & \multicolumn{2}{|c|}{ CS-rev. } \\
\hline Univ & Panel & Univ & Panel & Univ & Panel & Univ & Panel \\
\hline BEL & AUS & CAN & AUS & BEL & BEL & SWI & SWI \\
\hline CAN & BEL & FRA & BEL & CAN & CAN & SWE & SWE \\
\hline DEN & CAN & KOR & CAN & $\mathrm{DEN}$ & DEN & SAF & SAF \\
\hline FRA & DEN & POR & DEN & FRA & FRA & POR & POR \\
\hline GER & FRA & SWE & FRA & IRE & GER & KOR & LUX \\
\hline IRE & GER & UK & GER & ITA & IRE & GER & KOR \\
\hline ITA & IRE & & IRE & SAF & ITA & DEN & JAP \\
\hline JAP & ITA & & ITA & UK & JAP & AUS & ITA \\
\hline KOR & JAP & & JAP & & LUX & & IRE \\
\hline LUX & KOR & & KOR & & SAF & & GER \\
\hline NET & LUX & & LUX & & SWE & & DEN \\
\hline SWE & NET & & NET & & SWI & & CAN \\
\hline UK & POR & & POR & & UK & & AUS \\
\hline & SWE & & SAF & & & & \\
\hline & SWI & & SWE & & & & \\
\hline & UK & & SWI & & & & \\
\hline & & & UK & & & & \\
\hline
\end{tabular}

Notes: The columns denoted "Univ" refer to the univariate versions of the corresponding tests. The columns "Panel" refer to the SPSM. IPS, Pesaran and CS stand for Im, Pesaran, Shin (2003), Pesaran (2007) and Chang-Song (2009) tests, respectively. The ex post real rates are constructed as $r_{t}=i_{t}-\pi_{t+12}$, where $i_{t}$ and $\pi_{t+12}$ are the nominal interest rate at time $t$ and the inflation rate at time $t+12$, respectively. AUS: Austria, BEL: Belgium, CAN: Canada, DEN: Denmark, FIN: Finland, FRA: France, GER: Germany, IRE: Ireland, ITA: Italy, JAP: Japan, KOR: South Korea, LUX: Luxemburg, MEX: Mexico, NET: Netherlands, POR: Portugal, SAF: South Africa, SPA: Spain, SWE: Sweden, SWI: Switzerland, UK: United Kingdom. 
Table 4

Stationary Series: Long Run ex ante real rates

\begin{tabular}{|c|c|c|c|c|c|c|c|}
\hline \multicolumn{2}{|c|}{ IPS } & \multicolumn{2}{c|}{ PES } & \multicolumn{2}{c|}{ CS } & \multicolumn{2}{c|}{ CS-rev. } \\
\hline Univ & Panel & Univ & Panel & Univ & Panel & Univ & Panel \\
\hline CAN & BEL & AUS & AUS & CAN & CAN & SWI & UK \\
\hline FRA & CAN & CAN & BEL & DEN & DEN & SWE & SWI \\
\hline GER & DEN & FRA & CAN & FRA & FRA & SAF & SWE \\
\hline ITA & FRA & GER & DEN & SAF & ITA & POR & SAF \\
\hline JAP & GER & KOR & FRA & SWE & JAP & BEL & POR \\
\hline KOR & ITA & POR & GER & & KOR & & NET \\
\hline NET & JAP & SWE & ITA & & POR & & KOR \\
\hline POR & KOR & SWI & JAP & & SAF & & BEL \\
\hline SWE & NET & UK & KOR & & SWE & & AUS \\
\hline UK & POR & & LUX & & & & \\
\hline & SWE & & NET & & & & \\
\hline & SWI & & POR & & & & \\
\hline & UK & & SAF & & & & \\
\hline & & & SWE & & & & \\
\hline & & & SWI & & & & \\
\hline
\end{tabular}

Notes: The columns denoted "Univ" refer to the univariate versions of the corresponding tests. The columns "Panel" refer to the SPSM. IPS, Pesaran and CS stand for Im, Pesaran, Shin (2003), Pesaran (2007) and Chang-Song (2009) tests, respectively. The ex ante real rates are constructed as $r_{t}=i_{t}-E_{t} t t_{t}+2$, where $i_{t}$ and $\mathrm{E}_{\mathrm{t}} \pi_{t+12}$ are the nominal interest rate at time $t$ and the Markov-switching expected inflation rate for the $t+12$ period ahead. AUS: Austria, BEL: Belgium, CAN: Canada, DEN: Denmark, FIN: Finland, FRA: France, GER: Germany, IRE: Ireland, ITA: Italy, JAP: Japan, KOR: South Korea, LUX: Luxemburg, MEX: Mexico, NET: Netherlands, POR: Portugal, SAF: South Africa, SPA: Spain, SWE: Sweden, SWI: Switzerland, UK: United Kingdom. 
Table 5

Stationary Series: Short Run Contemporaneous real rates

\begin{tabular}{|c|c|c|c|c|c|c|c|}
\hline \multicolumn{2}{|c|}{ IPS } & \multicolumn{2}{c|}{ PES } & \multicolumn{2}{c|}{ CS } & \multicolumn{2}{c|}{ CS-rev. } \\
\hline Univ & Panel & Univ & Panel & Univ & Panel & Univ & Panel \\
\hline CAN & BEL & CAN & BEL & CAN & CAN & SWI & SWI \\
\hline DEN & CAN & DEN & CAN & DEN & DEN & SPA & SPA \\
\hline GER & DEN & FRA & DEN & FIN & FIN & MEX & SAF \\
\hline ITA & FIN & GER & FIN & GER & GER & KOR & MEX \\
\hline JAP & GER & KOR & FRA & ITA & ITA & JAP & KOR \\
\hline KOR & ITA & MEX & GER & JAP & JAP & ITA & JAP \\
\hline MEX & JAP & SPA & ITA & KOR & KOR & FRA & ITA \\
\hline SPA & KOR & SWI & JAP & MEX & MEX & DEN & FRA \\
\hline UK & MEX & UK & KOR & UK & SWI & BEL & DEN \\
\hline & SAF & & MEX & & UK & & BEL \\
\hline & SPA & & SAF & & & & \\
\hline & UK & & SPA & & & & \\
\hline & & & SWI & & & & \\
\hline & & & UK & & & & \\
\hline
\end{tabular}

Notes: The columns denoted "Univ" refer to the univariate versions of the corresponding tests. The columns "Panel" refer to the SPSM. IPS, Pesaran and CS stand for Im, Pesaran, Shin (2003), Pesaran (2007) and Chang-Song (2009) tests, respectively. The contemporaneous real rates are constructed as $r_{t}=i_{t}-\tau_{t}$, where $i_{t}$ and $\pi_{t}$ are the nominal interest rate and the inflation rate at time $t$, respectively. AUS: Austria, BEL: Belgium, CAN: Canada, DEN: Denmark, FIN: Finland, FRA: France, GER: Germany, IRE: Ireland, ITA: Italy, JAP: Japan, KOR: South Korea, LUX: Luxemburg, MEX: Mexico, NET: Netherlands, POR: Portugal, SAF: South Africa, SPA: Spain, SWE: Sweden, SWI: Switzerland, UK: United Kingdom. 
Table 6

Stationary Series: Short Run ex post real rates

\begin{tabular}{|c|c|c|c|c|c|c|c|}
\hline \multicolumn{2}{|c|}{ IPS } & \multicolumn{2}{c|}{ PES } & \multicolumn{2}{c|}{ CS } & \multicolumn{2}{c|}{ CS-rev. } \\
\hline Univ & Panel & Univ & Panel & Univ & Panel & Univ & Panel \\
\hline BEL & BEL & BEL & BEL & BEL & BEL & SWI & SWI \\
\hline CAN & CAN & CAN & CAN & DEN & DEN & SPA & SPA \\
\hline DEN & DEN & DEN & DEN & FIN & FIN & MEX & SAF \\
\hline JAP & FIN & FRA & FIN & GER & FRA & GER & MEX \\
\hline KOR & GER & MEX & FRA & ITA & GER & FIN & JAP \\
\hline MEX & ITA & SPA & GER & MEX & ITA & DEN & GER \\
\hline SPA & JAP & SWI & ITA & SPA & JAP & CAN & FIN \\
\hline UK & KOR & UK & JAP & UK & MEX & BEL & DEN \\
\hline & MEX & & KOR & & SPA & & CAN \\
\hline & SAF & & MEX & & UK & & BEL \\
\hline & SPA & & SAF & & & & \\
\hline & UK & & SPA & & & & \\
\hline & & & SWI & & & & \\
\hline & & & UK & & & & \\
\hline
\end{tabular}

Notes: The columns denoted "Univ" refer to the univariate versions of the corresponding tests. The columns "Panel" refer to the SPSM. IPS, Pesaran and CS stand for Im, Pesaran, Shin (2003), Pesaran (2007) and Chang-Song (2009) tests, respectively. The ex post real rates are constructed as $r_{t}=i_{t}-\pi_{t+12}$, where $i_{t}$ and $\pi_{t+12}$ are the nominal interest rate at time $t$ and the inflation rate at time $t+12$, respectively. AUS: Austria, BEL: Belgium, CAN: Canada, DEN: Denmark, FIN: Finland, FRA: France, GER: Germany, IRE: Ireland, ITA: Italy, JAP: Japan, KOR: South Korea, LUX: Luxemburg, MEX: Mexico, NET: Netherlands, POR: Portugal, SAF: South Africa, SPA: Spain, SWE: Sweden, SWI: Switzerland, UK: United Kingdom. 
Table 7

Stationary Series: Short Run ex ante real rates

\begin{tabular}{|c|c|c|c|c|c|c|c|}
\hline \multicolumn{2}{|c|}{ IPS } & \multicolumn{2}{c|}{ PES } & \multicolumn{2}{c|}{ CS-rev. } \\
\hline Univ & Panel & Univ & Panel & Univ & Panel & Univ & Panel \\
\hline BEL & BEL & DEN & BEL & BEL & BEL & UK & UK \\
\hline CAN & CAN & GER & CAN & DEN & DEN & SWI & SWI \\
\hline DEN & DEN & KOR & DEN & FIN & FIN & SPA & SPA \\
\hline FRA & FRA & MEX & FIN & GER & GER & SAF & SAF \\
\hline GER & GER & SPA & FRA & ITA & ITA & MEX & MEX \\
\hline ITA & ITA & UK & GER & JAP & JAP & KOR & KOR \\
\hline JAP & JAP & & ITA & KOR & KOR & JAP & JAP \\
\hline KOR & KOR & & JAP & SAF & MEX & ITA & ITA \\
\hline MEX & MEX & & KOR & SPA & SAF & GER & GER \\
\hline SAF & SAF & & MEX & SWI & SPA & FIN & FRA \\
\hline SPA & SPA & & SAF & UK & SWI & DEN & FIN \\
\hline UK & UK & & SPA & & UK & & DEN \\
\hline & & & SWI & & & & \\
\hline & & & UK & & & & \\
\hline & & & & & & & \\
\hline
\end{tabular}

Notes: The columns denoted "Univ" refer to the univariate versions of the corresponding tests. The columns "Panel" refer to the SPSM. IPS, Pesaran and CS stand for Im, Pesaran, Shin (2003), Pesaran (2007) and Chang-Song (2009) tests, respectively. The ex ante real rates are constructed as $r_{t}=i_{t}$-Et $\pi_{t+12}$, where $i_{t}$ and $E_{t} \tau_{t+12}$ are the nominal interest rate at time $t$ and the Markov-switching expected inflation rate for the $t+12$ period ahead. AUS: Austria, BEL: Belgium, CAN: Canada, DEN: Denmark, FIN: Finland, FRA: France, GER: Germany, IRE: Ireland, ITA: Italy, JAP: Japan, KOR: South Korea, LUX: Luxemburg, MEX: Mexico, NET: Netherlands, POR: Portugal, SAF: South Africa, SPA: Spain, SWE: Sweden, SWI: Switzerland, UK: United Kingdom. 


\section{Table 8}

Half-Lives

\begin{tabular}{|c|c|c|c|}
\hline & Contemporaneous & Ex post & Ex ante \\
\hline & \multicolumn{3}{|c|}{ Long-run rates } \\
\hline Average & 20.844 & 24.769 & 16.732 \\
\hline Panel-All & 15.838 & 19.670 & 12.913 \\
\hline Panel-SPS & 13.570 & 17.869 & 15.450 \\
\hline Average & 16.299 & Short-run rates & 8.509 \\
\hline Panel-All & 9.208 & 17.540 & 8.215 \\
\hline Panel-SPS & 8.991 & 12.497 & \\
\hline & & & 12.428 \\
\hline
\end{tabular}

Notes: Numbers refer to months. 'Average' refers to average individual half-lives. Panel-All refers to panel half-lives when all series are included in the panel, while Panel-SPS refers to panel half-lives when only the stationary series are included. 